\title{
The Research of Anti-Swelling and Low Damage Killing Fluid System
}

\author{
Qinggong DANG, Hui JIA, Shuang SUN, Meng LI, Zhenqi JIA \\ College of Petroleum Engineering, Daqing Petroleum Institute, Daqing, China \\ Email:dangqg@sina.com
}

\begin{abstract}
In this paper, we introduced reservoir characteristics in Block Xiao-he-long and evaluate the performance of the existing killing fluid system. According to the production requirements, a anti-swelling and low damaging system of chemical agents suitable for this block was optimized, including anti-swelling agent, water lock inhibitor, fluid-loss agent additives, plus a corrosion inhibitor HS-1 developed by in the lab. The system is composed by base liquid $(0.7 \% \mathrm{X}+2.0 \% \mathrm{KCl}+0.05 \% \mathrm{SY}-1+0.05 \% \mathrm{HS}-1+2.0 \%$ DST- 1 dissolved in water) and weighting material $(\mathrm{NaCl})$ with its density adjustable range between $1.0 \mathrm{~g} / \mathrm{ml}$ and $1.2 \mathrm{~g} / \mathrm{ml}$. Its anti-swelling ratio achieves $53.80 \%$, and the reservoir permeability recovery ratio reaches more than $95.0 \%$.
\end{abstract}

Keywords: killing fluid, fomula, reservoir protect, low permeability

\section{Reservoir Characteristics}

Information shows that gas is produced mainly in sections of Quantou1 (Q1) and Quantou3 (Q3) at Block Xiao-he-long. The formations are composed of mudstone, sandy mudstone, siltstone and gravel rough rock with higher clay content, generally, more than $95.0 \%$. In addition, the layer also contains a certain amount of Fe-Al minerals and carbonate minerals. Sections of Q1 and Q3 are high in salinity, of which the average number is $17098.4 \mathrm{mg} / \mathrm{l}$, maximum number up to $23216.5 \mathrm{mg} / \mathrm{l}$, minimum value by $122.43 .3 \mathrm{mg} / \mathrm{l}$. The formation water is a kind of kalescent fluid of $\mathrm{NaHCO}_{3}$, of which the $\mathrm{Ph}$ values are between 7.0 and 8.5 with the average value by 7.6. Studies show that this block has poor reservoir properties. The injected fluid such as water, acid or alkaline liquid would give rise to the sensitivity reaction easily to cause serious damage to the reservoir.
The average pressure coefficients of Sections of Q1 and Q3 fall between 0.995 and 1.05 while the average temperature gradients are between 4.21 and $4.75^{\circ} \mathrm{C}$ per $100 \mathrm{~m}$. So they are systems with normal pressure and temperature. Based on the requirements of well control management, killing fluid density should be equal to the value of pressure coefficient plus 0.07-0.15. Therefore, the killing fluid density can meet the production requirements of Block Xiao-he-long when the density are between 1.065 and $1.20 \mathrm{~g} / \mathrm{ml}$.

\section{Existing Killing Fluid Performance}

Here we evaluated the conventional performance of three killing fCluids (Density, Viscosity, Ph value, fluid loss volume and stability performance) which are used at the Block Xiao-he-long. The results are presented in Table 1.

Table 1. Results of evaluation existing killing fluid performance

\begin{tabular}{ccccccccc}
\hline \multirow{2}{*}{ Killing fluid code } & Density $\left(\mathrm{g} / \mathrm{cm}^{3}\right)$ & Viscosity $(\mathrm{mPa} \cdot \mathrm{s})$ & $\mathrm{Ph}$ & Fluid-loss volume $(\mathrm{ml})$ & Stability performance & \multicolumn{2}{c}{ Reservoir damage ratio \% } \\
\hline 1\# & 1.23 & 75.0 & 11 & serious & well & 88.51 & 96.97 \\
1\# & 1.01 & 37.5 & 7 & $>50$ & well & 92.86 & 97.95 \\
3\# & 1.19 & 14.5 & 8 & $>50$ & well & 76.62 & 83.16 \\
\hline
\end{tabular}


We can see from Table 1 that the existing killing fluids have good index as stability performance, density and viscosity to meet the operational requirements. But the fluid-loss volumes are too big as the fluid damage rate of the three killing fluids are more than $75 \%$ and the value of $2 \#$ is as high as $97.95 \%$. It no longer satisfies the requirements of the oil and gas reservoir protection.

\section{Development of the Killing Fluid System of Anti-Swelling with Low Damage}

Based on the reservoir characteristics of Block Xiao-helong, a number of anti-swelling agents, water lock inhibitors, corrosion inhibitors and fluid-loss agents and several additives are studied and optimized.

\subsection{Research of Anti-Swelling System}

In this section, we used dilatometer NP-1 to study the anti-swelling effect of $\mathrm{KCl}$ and small cation $\mathrm{X}$, and to determine the anti-swelling system suitable for Block Xiao-he-long. The results are presented in Table 2.

Experimental results show that anti-swelling effect increases with the increment of $\mathrm{KCl}$ and $\mathrm{X}$. When the amounts of $\mathrm{X}$ and $\mathrm{KCl}$ reach $0.7 \%$ and $2.0 \%$, respectively, there will be a good anti-swelling effect with the anti-swelling ratio by $53.80 \%$.

\subsection{Screening Water Lock Inhibitor}

In order to avoid the water lock effect, a few of water lock inhibitor need to be added to the killing fluid. SY-1 and SY-2 have excellent ability to inhibit the water lock effect. Effects of the base liquid with $0.7 \% \mathrm{~A}$ and $2.0 \% \mathrm{KCl}$ on the ratio of reservoir damage are shown in Table 3 .

Table 2. The experimental results of anti-swelling system

\begin{tabular}{ccccc}
\hline anti-swelling agents and the dosages & $\mathrm{X}(0.5 \%) \mathrm{KCl}(1.2 \%)$ & $\mathrm{X}(0.7 \%) \mathrm{KCl}(1.2 \%)$ & $\mathrm{X}(0.5 \%) \mathrm{KCl}(2.0 \%)$ & $\mathrm{X}(0.7 \%) \mathrm{KCl}(2.0 \%)$ \\
\hline Swelling extent (mm) 24h & 1.31 & 1.24 & 1.18 & 1.11 \\
Ratio (\%) & 5.82 & 5.51 & 5.24 & 5.93 \\
Anti-swelling ratio (\%) & 45.45 & 48.36 & 50.89 & 53.80 \\
\hline
\end{tabular}

Table 3. The effect of water lock inhibiter on reservoir damage ratio

\begin{tabular}{ccc}
\hline Water lock inhibiter & Amount (\%) & Reservoir damage ratio (\%) \\
\hline SY-1 & 0.05 & 9.70 \\
SY-2 & 0.05 & 20.49 \\
\hline
\end{tabular}

Table 4. Experimental results of the HS-1 anti-corrosion ability

\begin{tabular}{ccc} 
Amount of HS-1 (\%) & Temperature $\left({ }^{\circ} \mathrm{C}\right)$ & Corrosion rate $(\mathrm{mm} / \mathrm{d})$ \\
\hline 0.00 & 80.0 & 1.089 \\
0.05 & 80.0 & 0.051 \\
\hline
\end{tabular}

Table 3 shows that the water lock inhibitor added to the killing fluid can reduce the reservoir damage ratio. SY-1, which is better than SY-2, could reduced damage ratio to $9.70 \%$. Therefore, we choose SY-1 for this system to control water lock.

\subsection{Corrosion Inhibitor HS-1}

In order to slow down the corrosion rate of the tubing and casing, we developed the corrosion inhibitor HS-1 for this killing fluid system. Table 4 is the experimental results of the HS-1 anti-corrosion ability.

Experimental results shown that a certain amount of HS-1 to the killing fluid can reduce the corrosion rate in comparison with the pre-accession. Thus we know that 


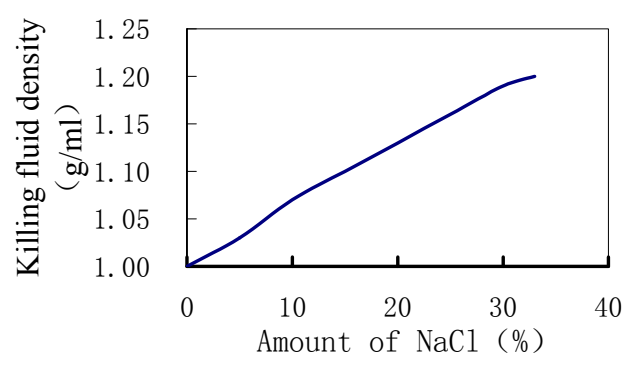

Figure 1. Relationship between the amount of $\mathrm{NaCl}$ and killing fluid density

HS-1 has good corrosion inhibition ability.

\subsection{Density Adjustment}

Block Xiao-he-long was buried shallow and has low formation pressure, so $\mathrm{NaCl}$ is used to adjust the density of the killing fluid to meet the requirements of killing well. Figure 1 shows the relationship between the correlation of the killing fluid density versus the amount of $\mathrm{NaCl}$.

\subsection{Screening Fluid-Loss Agent}

We screen a variety of fluid-loss agent to reduce the fluid-loss volume. Finally, we selected SPN-1 and SPN-2 as the fluid-loss agent. And then, we studied the effects of mixed system and the individual agent. The results are presented in Table 6.

DST-1 (SPN-1: SPN-2 = 3:2) and DST-2 (SPN-1: SPN-2 = 1:1) were mixture of SPN-1 and SPN-2. Table 6 shown that system with both SPN-1 and SPN-2 is better than single one agent while DST-1 is the best with the least of fluid-loss volume of $5.0 \mathrm{ml} / \mathrm{min}$ (API).

Both SPN-1 and SPN-2 can form polymeric membrane on rock surface to reduce the killing fluid fluid-loss volume. On the rock surface the mixture of SPN-1 and SPN-2 will form micellar of different size
Table 6. Results of screening fluid-loss agent

\begin{tabular}{ccccc}
\hline $\begin{array}{c}\text { Fluid-loss } \\
\text { agent }\end{array}$ & $\begin{array}{c}\text { Amount } \\
(\%)\end{array}$ & $\begin{array}{c}\text { Viscosity } \\
(\mathrm{mPa} \cdot \mathrm{s})\end{array}$ & $\begin{array}{c}\text { Density } \\
\left(\mathrm{g} / \mathrm{cm}^{3}\right)\end{array}$ & $\begin{array}{c}\text { Fluid-loss } \\
\text { Volume (ml/API) }\end{array}$ \\
\hline SPN-1 & 2.0 & 4.62 & 1.10 & 7.9 \\
SPN-2 & 2.0 & 8.25 & 1.12 & 12.5 \\
DST-1 & 2.0 & 5.80 & 1.10 & 5.0 \\
DST-2 & 2.0 & 6.53 & 1.09 & 6.7 \\
\hline
\end{tabular}

and shape which complement each other to form a more dense-permeable membrane to reduce the killing fluid loss. Therefore, DST-1 is chosen as the system fluid-loss agent.

\subsection{Summary}

In sum of the above studies, we have obtained the anti-swelling and low damage killing fluid system suit able for Block Xiao-he-long. It is composed by base liquid $(0.7 \% \mathrm{X}+2.0 \% \mathrm{KCl}+0.05 \% \mathrm{SY}-1+0.05 \% \mathrm{HS}-1+2.0 \%$ DST-1 dissolved in water) and weighting material $(\mathrm{NaCl})$.

\section{Evaluation of Anti-Swelling and Low Damage Killing Fluid}

According to the formula in $F$, three configurations of different killing fluids are made as $4 \#, 5 \#$ and $6 \#$ which are evaluated in experiments. The results are shown in Table 7.

Table 7 shows that the anti-swelling and low damage killing fluid have good index as the stability performance, low viscosity, Ph value by 7.0. It will not give rise to acid and alkali damage. The fluid-loss volume is about

Table 7. Results of evaluation the performance of anti-swelling and low damage killing fluid

\begin{tabular}{|c|c|c|c|c|c|c|c|}
\hline \multirow{2}{*}{ Killing fluid code } & \multirow{2}{*}{ Density $\left(\mathrm{g} / \mathrm{cm}^{3}\right)$} & \multirow{2}{*}{ Viscosity $(\mathrm{mPa} \cdot \mathrm{s})$} & \multirow{2}{*}{$\mathrm{Ph}$} & \multirow{2}{*}{ Fluid-loss volume (ml) } & \multirow{2}{*}{ Stability performance } & \multicolumn{2}{|c|}{ Reservoir damage ratio \% } \\
\hline & & & & & & Q1 & Q3 \\
\hline $4 \#$ & 1.02 & 5.76 & 7.0 & 4.5 & Well & 3.98 & 3.70 \\
\hline $5 \#$ & 1.11 & 5.78 & 7.0 & 5.5 & Well & 4.33 & 4.25 \\
\hline
\end{tabular}


$7.0 \mathrm{ml} / 30 \mathrm{~min}$. Its damage to the reservoir is low, and the reservoir permeability recovery is more than $95.0 \%$.

\section{Conclusions}

1) A killing fluid system of anti-swelling and low damage is developed with its anti-swelling ratio up to $53.80 \%$;

2) The anti-swelling and low damage killing fluid system have low fluid-loss volume by $7.0 \mathrm{ml} / 30 \mathrm{~min}$ (API) no matter how much killing fluid density. It can recovery the reservoir permeability value more than $95.0 \%$;

3) A series of additives and their dosages are optimized for this anti-swelling and low damage killing fluid system. The system is composed by base liquid $(0.7 \% \mathrm{X}$
$+2.0 \% \mathrm{KCl}+0.05 \% \mathrm{SY}-1+\quad 0.05 \% \mathrm{HS}-1+2.0 \%$ DST- 1 dissolved in water) and weighting material $(\mathrm{NaCl})$. It is better than existing killing fluids and can satisfy the requirements of oil and gas layer protection in Block Xiao-he-long.

\section{REFERENCES}

[1] SY/T5358-2002, "Formation damage evaluation by flow test," S.

[2] Fan Shizhong, "Oil and gas layer protection and evaluation," Petroleum Industry Press, Beijing, pp. 92-126, 1988.

[3] Xu Tongtai, Zhao min, and Xiong Youming, "Protection oil and gas layer technology,” Oil Press, Beijing, pp. 49-55, 2003.

[4] Li Kexiang, "Oil and gas layer drilling and killing well technology," Petroleum Industry Press, pp. 796-815, Beijing, 1993. 